HAVANA PAPER

\title{
Outreach and improved access to specialist services for indigenous people in remote Australia: the requirements for sustainability
}

\author{
R L Gruen, T S Weeramanthri, R S Bailie
}

J Epidemiol Community Health 2002;56:517-521

See end of article for authors' affiliations

Correspondence to: Dr R L Gruen, Menzies School of Health Research, PO Box 41096 ,

Casuarina, NT 0811

Australia;

russg@menzies.edu.au

Accepted for publication 5 January 2002

\begin{abstract}
Study objective: To examine the role of specialist outreach in supporting primary health care and overcoming the barriers to health care faced by the indigenous population in remote areas of Australia, and to examine issues affecting its sustainability.

Design: A process evaluation of a specialist outreach service, using health service utilisation data and interviews with health professionals and patients.

Setting: The Top End of Australia's Northern Territory, where Darwin is the capital city and the major base for hospital and specialist services. In the rural and remote areas outside Darwin there are many small, predominantly indigenous communities, which are greatly disadvantaged by a severe burden of disease and limited access to medical care.

Participants: Seventeen remote health practitioners, five specialists undertaking outreach, five regional health administrators, and three patients from remote communities.

Main results: The barriers faced by many remote indigenous people in accessing specialist and hospital care are substantial. Outreach delivery of specialist services has overcome some of the barriers relating to distance, communication, and cultural inappropriateness of services and has enabled an over fourfold increase in the number of consultations with people from remote communities. Key issues affecting sustainability include: an adequate specialist base; an unmet demand from primary care; integration with, accountability to and capacity building for a multidisciplinary framework centred in primary care; good communication; visits that are regular and predictable; funding and coordination that recognises responsibilities to both hospitals and the primary care sector; and regular evaluation. Conclusions: In a setting where there is a disadvantaged population with inadequate access to medical care, specialist outreach from a regional centre can provide a more equitable means of service delivery than hospital based services alone. A sustainable outreach service that is organised appropriately, responsive to local community needs, and has an adequate regional specialist base can effectively integrate with and support primary health care processes. Poorly planned and conducted outreach, however, can draw resources away and detract from primary health care.
\end{abstract}

$\mathrm{S}$ pecialist outreach can only promote equity of access when it considers both the needs of remote communities and the adequacy of the specialist base.

In this journal, Bond et al ${ }^{1}$ have shown that specialist clinics conducted in primary care settings result in improved patient satisfaction, improved access to specialist care, and greater likelihood of discharge from care. While in the UK improvements in health outcomes seem to be small and costs are not reduced,,$^{1-4}$ the potential benefits of outreach are more evident in settings where specialist care is otherwise relatively inaccessible. ${ }^{56}$

To reduce distance barriers faced by rural and remote Australian communities, a number of specialists have provided visiting services from regional centres. Only some of these outreach programmes have been sustained. Most often they have been organised on an ad hoc basis, without a systematic approach to the determination of needs and the provision of services.

One particular outreach service was recently established in northern Australia with the goal of improving access to specialist care for indigenous people in remote communities. It was evaluated using measures of health service utilisation and in depth, semistructured interviews with 17 remote clinic staff (seven doctors, five nurses, and five Aboriginal health workers), and with five specialists conducting outreach, five regional health service administrators, and three patients in remote communities. ${ }^{8}$ The evaluation methods and the findings of improved access to specialist care have been reported. ${ }^{9}$ This paper briefly reviews the background of the service and the key findings of the evaluation, and then discusses the prerequisites for sustainable and effective outreach in local and international contexts.

\section{THE HEALTH OF INDIGENOUS PEOPLE IN THE TOP END OF AUSTRALIA'S NORTHERN TERRITORY}

The Northern Territory (NT) is the most sparsely populated region in Australia. The "Top End" occupies the northern third, an area of 516945 square kilometres with a tropical monsoonal climate. It has a population of 148641 of whom 105730 live in Darwin, the capital city. Indigenous people comprise only $8 \%$ of the population of Darwin, but account for $52 \%$ in the remainder of the Top End, and most live in small remote communities (fig 1). Such communities have populations of up to 2000, and act as service centres for smaller outstations or homelands, with between 10 and 100 residents. Most communities have a store, an airstrip, a school, and a health clinic staffed by nurses and Aboriginal health workers. Primary care physicians are resident in many larger communities and visit smaller communities regularly.

Australia's indigenous population are greatly disadvantaged, as measured by a broad range of health and social welfare indicators, ${ }^{10}$ and their health has failed to improve like that of some indigenous communities within other developed 


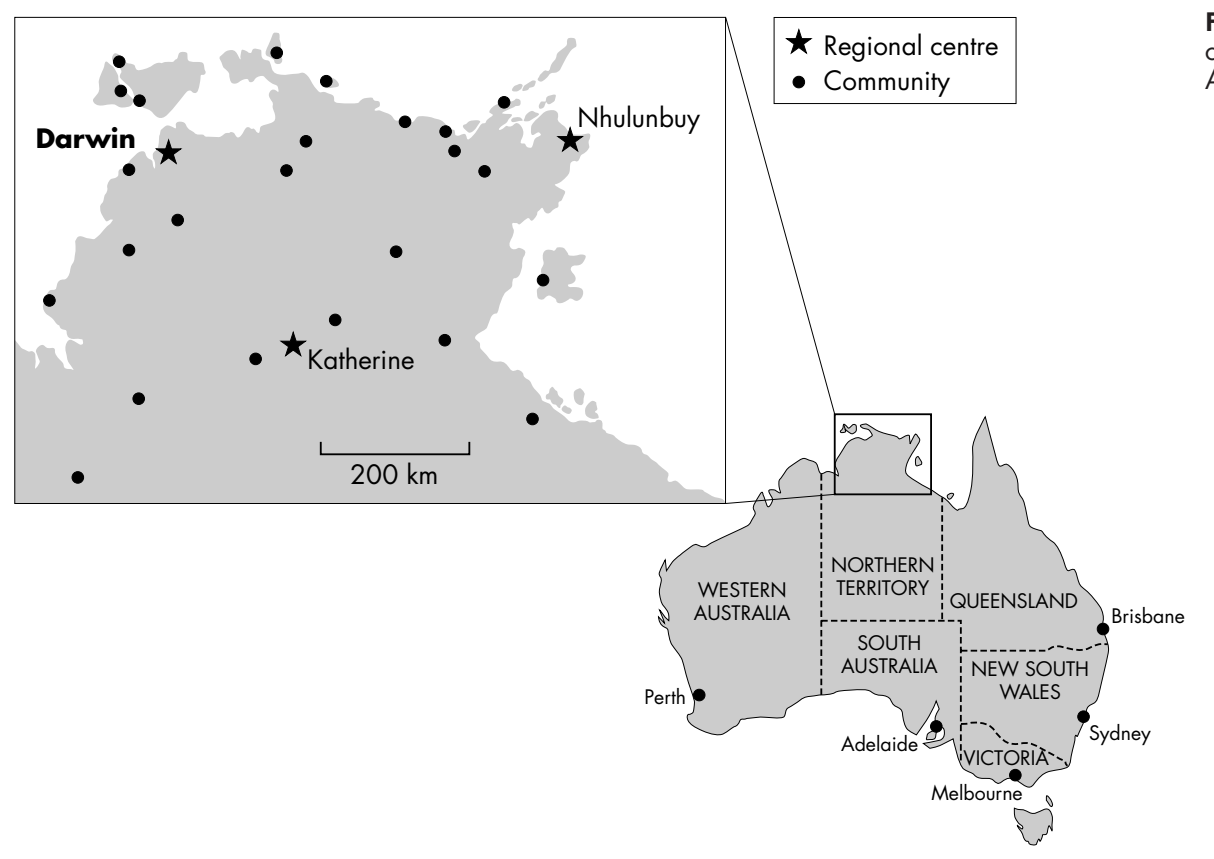

Figure 1 The larger indigenous communities in the Top End of Australia's Northern Territory.

countries. ${ }^{11}$ They have a well documented history of alienation, discrimination, and dispossession from land, ${ }^{12}$ and a fundamental challenge lies in tackling the marginalised position of indigenous people within Australian society. Public health challenges that remain unmet, such as clean water, effective sanitation, adequate housing, and a healthy food supply, are especially acute in rural and remote areas.

Indigenous Australians face substantial problems in accessing a variety of services, including appropriate primary health care. Many of the diseases that are responsible for their greater morbidity and mortality would ordinarily be managed with the involvement of specialists in urban Australian settings. ${ }^{10} 13$ Relative to their needs, however, indigenous people use hospital and specialist services less than non-indigenous people. ${ }^{14-16}$ Those from remote communities in the NT have higher rates of cancellations and non-attendance at appointments, and more frequently discharge themselves prematurely against medical advice. The barriers they face when accessing hospital based specialist services were identified through interviews with remote clinic staff, patients, and specialists (table 1).

\section{THE SPECIALIST WORKFORCE AND SPECIALIST OUTREACH}

Australia as a whole has a large specialised medical workforce but its distribution is inequitable, with most choosing to work in capital cities. Twenty eight per cent of the Australian population, but only $12 \%$ of specialists, live in rural and remote areas. ${ }^{17}$ There are approximately 75 specialists in the Top End of the NT, and all are based in Darwin where there is a 300 bed public hospital and a private hospital. To access specialist care in the public system, referral by a primary care practitioner (usually a doctor) is required.

While some specialists, particularly those in internal medicine and paediatrics, have for many years independently integrated regular outreach visits with their Darwin based practices, special financing from the Australian and NT Governments has enabled other specialties to be coordinated in a recently established multidisciplinary outreach service. The Specialist Outreach Service (SOS) covers the salary of a full time obstetrician/gynaecologist, remunerates an ophthalmologist, five general surgeons, and an otolaryngologist from Royal Darwin Hospital on a sessional basis, and employs a full time coordinator and an administrative assistant.

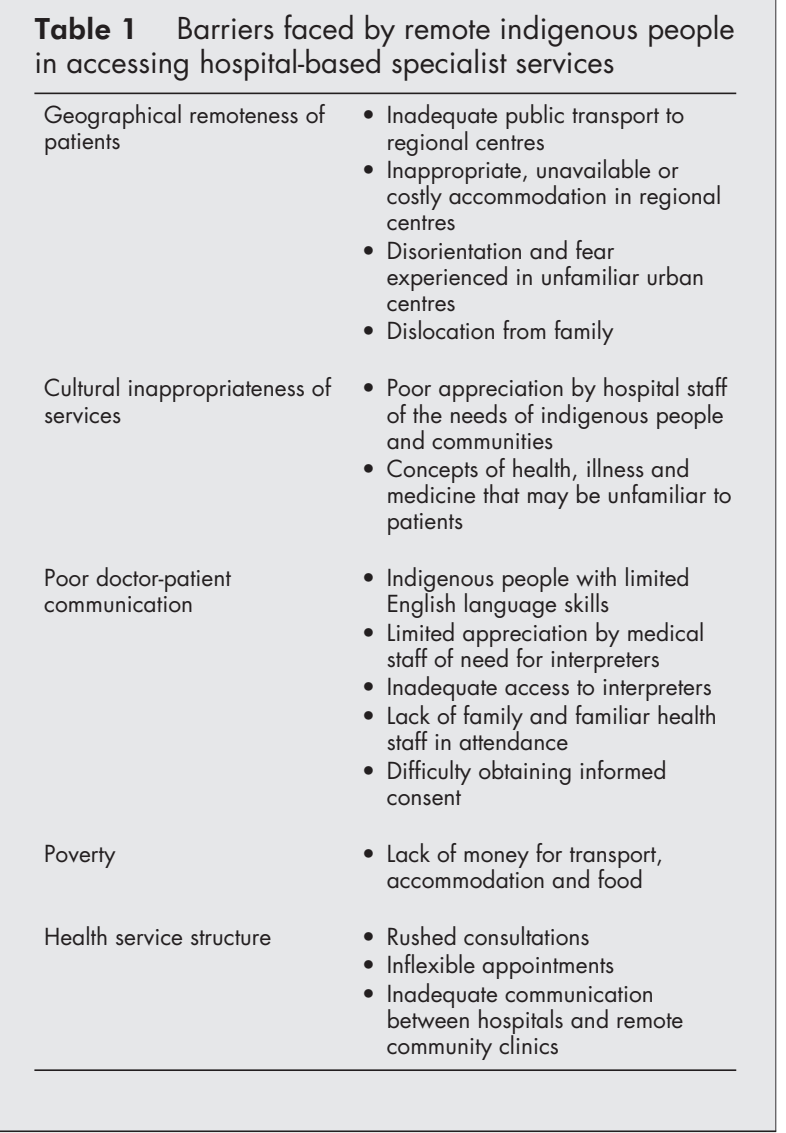

Specialist visits are usually one or two days in duration. The nature of the service provided differs for each discipline. Many consultations are non-procedural, instead providing specialist opinion for a broad range of conditions, and improving access to or follow up after major operations at regional hospitals where modern operating theatres and staff are available. Forty seven per cent of new referrals to a general surgeon and 30\% to the ophthalmologist resulted in hospital based investigation or treatment. 


\begin{tabular}{|c|c|}
\hline \multicolumn{2}{|c|}{$\begin{array}{l}\text { Table } 2 \text { Benefits of specialist outreach in the } \\
\text { Northern Territory }\end{array}$} \\
\hline $\begin{array}{l}\text { No need for patients to travel } \\
\text { large distances }\end{array}$ & $\begin{array}{l}\text { - More patients seen } \\
\text { - Less disruption to families and } \\
\text { workplace, less cost of transport } \\
\text { and accommodation }\end{array}$ \\
\hline $\begin{array}{l}\text { Family and health staff in } \\
\text { attendance }\end{array}$ & $\begin{array}{l}\text { - Improved practitioner and } \\
\text { patient understanding of clinical } \\
\text { and management issues } \\
\text { - Improved doctor-patient } \\
\text { communication }\end{array}$ \\
\hline $\begin{array}{l}\text { Specialist works within } \\
\text { community context }\end{array}$ & $\begin{array}{l}\text { - Improved cultural appreciation } \\
\text { by specialists and hospital } \\
\text { systems }\end{array}$ \\
\hline $\begin{array}{l}\text { Specialist interaction with } \\
\text { primary care practitioners }\end{array}$ & $\begin{array}{l}\text { - Improved communication } \\
\text { between hospital staff and } \\
\text { remote clinic staff } \\
\text { - Education and training } \\
\text { opportunities }\end{array}$ \\
\hline Cost & $\begin{array}{l}\text { - Cost savings when compared } \\
\text { with the transport of patients to } \\
\text { regional centres }\end{array}$ \\
\hline
\end{tabular}

Only surgical procedures that can safely be performed under a local anaesthetic, such as biopsies, vasectomies, and circumcisions, are undertaken on site, as are other specialist procedures that are beyond the current capacity of primary care. These include comprehensive eye examinations and screening for retinopathy, antenatal ultrasound, and colposcopy and biopsy using a mobile colposcope. Forty seven per cent of referrals to the outreach obstetrician/gynaecologist, for example, were for women with abnormal cervical cytology.

\section{THE IMPACT OF SPECIALIST OUTREACH}

The annual number of consultations with people from remote communities has increased over fourfold since the introduction of outreach, and the data for the visiting gynaecologist are given in figure 2. Corresponding increases have not been observed in those specialties without outreach. The increase reflects fewer difficulties faced by patients in attending their appointments, and a lower threshold for referral by remote practitioners because of fewer perceived barriers. The benefits of outreach in this setting, reported by remote health practitioners, patients, and specialists, are detailed in table 2 .

The average cost per consultation was less through outreach $(\mathrm{A} \$ 277)$ than it would have been bringing the same patients to the outpatient clinic in Darwin (A \$450). In many cases the SOS is meeting previously unmet needs. In some instances, it is obviating the need for hospitalisation (for example, only $45 \%$ of women undergoing colposcopy subsequently needed hospital treatment, and local practitioners were trained in screening for retinopathy), but in others it is appropriately increasing the demand for hospital based care (for example, identification of high risk pregnancies, cataract, and established retinopathy).

\section{REQUIREMENTS FOR A SUSTAINABLE SPECIALIST OUTREACH SERVICE}

A high priority of the formative evaluation was to identify aspects of specialist outreach that remote practitioners, specialists, and administrators felt were likely to influence its sustainability. These are summarised in table 3.

Specialists explained that a hospital base is essential, particularly in the procedural specialties, because it enables continuity of care for patients who require inpatient management, and it enhances relations with and referral pathways to

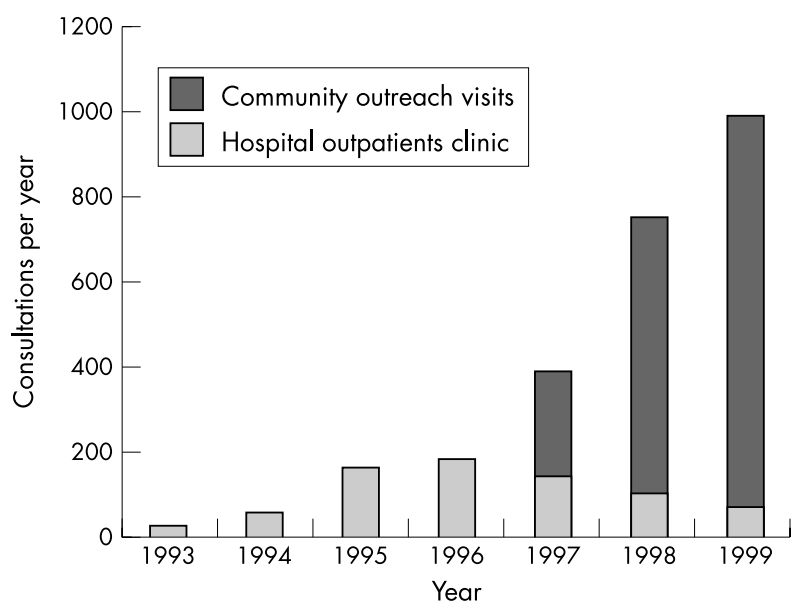

Figure 2 Number of consultations by a specialist gynaecologist with women from remote communities in the Top End of the Northern Territory 1993-1999.

other specialists. Both specialists and hospital administrators, however, acknowledged potential conflict between hospital commitments and outreach roles. When a specialist is undertaking outreach there are opportunity costs, and colleagues usually take on additional hospital duties. In hospitals with sufficient specialist staff, and where outreach is integrated and a valued part of service provision, outreach is unlikely to disrupt functions of the hospital. On the other hand, where there are few specialists in one centre (as may be the case for particular disciplines such as otolaryngology, or in smaller regional centres), specialists feel that hospital based activities make more efficient use of their time than do outreach clinics.

Clearly outreach is demanding for specialists, as it entails early departures, late returns, overnight stays, and often combines travel over large distances with a day of consulting and procedures. The responsibility for outreach in any specialty should be shared as much as possible. Services that are

Table 3 Requirements for sustainable specialist outreach in the Northern Territory

\begin{tabular}{|c|c|}
\hline $\begin{array}{l}\text { Specialist base } \\
\text { considerations }\end{array}$ & $\begin{array}{l}\text { - Adequate number of specialists } \\
\text { - Outreach is integrated, valued, and } \\
\text { facilitated } \\
\text { - Outreach specialist has a hospital } \\
\text { role } \\
\text { - Outreach is shared and not } \\
\text { dependent on one person }\end{array}$ \\
\hline Primary care considerations & $\begin{array}{l}\text { - Adequately resourced and staffed } \\
\text { - Demand exists for specialist care } \\
\text { - A multidisciplinary framework } \\
\text { centered in primary care and not } \\
\text { dominated by specialists }\end{array}$ \\
\hline The outreach service & $\begin{array}{l}\text { - Coordination and prior planning of } \\
\text { visits } \\
\text { - Funded separately } \\
\text { - Evaluated regularly }\end{array}$ \\
\hline The nature of outreach visits & $\begin{array}{l}\text { - Regular and predictable } \\
\text { - Respond to individual community } \\
\text { needs } \\
\text { - Accountable to the referring } \\
\text { practitioner and community } \\
\text { - Appropriate mix of clinical services, } \\
\text { education and support } \\
\text { - Utilise education and training } \\
\text { opportunities } \\
\text { - Reliable correspondence and good } \\
\text { communication }\end{array}$ \\
\hline
\end{tabular}




\section{Key points}

- Indigenous people face substantial barriers when accessing hospital based specialist care.

- Specialist outreach services have been developed to compensate for the lack of specialists practising in rural and remote areas.

- Outreach from a regional centre improves access to specialist care for indigenous people in remote communities.

- Appropriate specialist outreach can effectively support existing primary health care activities in remote communities.

- Sustainability depends on an adequate specialist base, integration with remote communities, and attention to organisation and funding issues.

dependent on one person are vulnerable, and provision for illness, resignation, or retirement should be incorporated. Additionally, changes and cancellations of visits at short notice are very disruptive for remote health clinics.

All parties clearly expressed the view that outreach visits are more likely to run smoothly and be efficiently integrated with other clinic activities when remote clinics are well staffed. Such integration into the remote community clinics' programmes also helps to ensure that outreach responds to the needs of each community, building on the resources and skills that are available locally. Remote staff considered it important that they participate in the scheduling of visits, have formal channels of feedback, and that services are evaluated regularly.

While specialists conducting outreach were familiar with difficulties and resource constraints facing most remote clinics, many were still frustrated by delays in patients coming to the clinic, and inadequate support staff to make the most of their visits. Primary care practitioners acknowledged such difficulties, and explained that these difficulties are minimised when the specialist visits are regular and predictable, well coordinated, and patients have prior notification. This was best managed by both specialists and primary carers keeping lists of patients that they think need to be seen, and reconciling those lists before and after each visit. Towards this end, the coordinator has a key role liaising with specialists and remote clinics, as well as planning visits, organising equipment, and ensuring good communication and timely correspondence.

\section{DISCUSSION}

In Australia, as elsewhere, there are many motives for providing specialist services on an outreach basis, and often provider interests drive them, at least initially. In the Top End of the NT there are large distances and costs of bringing people to hospitals, a large proportion of indigenous people with a high burden of severe and advanced disease, complex cross cultural and communication issues, and an under-resourced primary health care sector. We have shown specialist outreach improves access in this context but, depending on how it is organised, it may or may not be sustainable.

After a survey of 20 Australian specialist colleges, the Australian Medical Workforce Advisory Committee (AMWAC) has defined a sustainable specialist service as one that "is clinically appropriate and adaptable to the needs and expectations of the local community, is provided on a regular basis and is well integrated with local primary care services." ${ }^{7}$ Responding to the demands of primary care requires much more than enumeration of remote populations-it includes consideration of the demographics of disease and the capacity of primary care services.

In remote communities specialists must work as part of a multidisciplinary health care team centred in primary care.
Specialist outreach should tailor its arrangements to use the full potential of primary care resources while providing needed skills and resources that are not present locally. This can only be achieved if the service is accountable to the referring primary care practitioners and the local communities, and if the service is evaluated regularly. The provision of education and skills transfer, as well as professional and emotional support, is likely to enhance the capacity of primary care.

The role of specialists delivering services to rural and remote indigenous communities has been addressed in a consensus statement drawn up by specialists from a variety of professional colleges-the 1997 Cottrell Declaration. ${ }^{* 18}$ It emphasied that good two way communication between specialists and patients is a prerequisite to safe and effective care, to patient satisfaction, and to informed consent. The interviewees in this study also emphasised the importance of providing a culturally appropriate service, perhaps through a greater involvement of indigenous health workers, and use of interpreters. They predicted that this will lead, through better communication, to improved understanding by patients of their illness and treatment, and improved understanding of the community context by specialists.

At the Cottrell Conference it was agreed that medical specialists can best deliver appropriate, effective, high quality care if primary care services are adequately funded and running well. While additional investment in primary health care is to be encouraged, Australian health funding arrangements make it likely that the specialty and hospital sectors will continue to receive a large proportion of the health budget. This is where there is a potential danger: improving specialist services without improving primary care services could worsen, rather than improve, health outcomes, if the efforts draw resources away from primary care.

Adequate specialist resources are also essential. For outreach to be sustainable, a regional centre requires sufficient specialists in each discipline to provide regular outreach services to outlying communities and an organisational structure in which outreach is an accepted part of normal practice. If there is not, it is probable that outreach visits will be foregone when pressing demands occur at the hospital base. Paediatricians and adult physicians have sustained an outreach service from Royal Darwin Hospital for over 20 years because of personal commitment and an adequate specialist base, but coverage and accountability improved when community based specialists were appointed and took on a coordinating role. ${ }^{17}$ Indeed, the success of the SOS was probably also predicated on the existence of a regional hospital that already employed large numbers of specialists. In many parts of Australia, such regional centres either do not exist or are poorly resourced and staffed, and may therefore be unable to sustain an outreach service.

While outreach reduces the costs of patient travel in this setting, the benefits may not be so apparent within the government health sector, where the financing of travel and specific health services are often separate and difficult to link. Ideally specialist outreach services should be funded separately, employ an organisational structure that can be

*Forty eight people attended the Cottrell Conference by invitation from the Royal Australasian College of Physicians, nominated by their peers and professional colleges because of their experience working with indigenous communities in rural and remote Australia. The vast majority were practising medical specialists across a range of disciplines, but a small number of primary care practitioners, nurse practitioners, and Aboriginal health workers were also invited. (People involved only from a policy or academic viewpoint were not invited.) This was a unique gathering of such specialist expertise, and while not strictly "representative" of all specialists working in rural and remote Australia was certainly the largest such gathering ever held to discuss specifically the delivery of specialist services to Indigenous communities. 
integrated with the specialist and primary health care sectors, and be responsive to the needs of both. Public specialist medical services in Australia are usually the responsibility of the individual states and territories, but this pilot outreach project was supported by dedicated Federal Government funds. Methods of financing specialist outreach are currently being explored at a national level such that some of the financial and administrative disincentives are reduced.

Sustaining a service is one issue, but evaluating long term health outcomes is another, and is the subject of further study. However, it is likely to be some time before more definitive data on impact and outcomes of specialist outreach in different settings are available. In the meantime, the delivery of specialist services on an outreach basis is justified, at least in developed countries such as Australia, purely on the basis of equity of access. We need to continue to reflect on ways to deliver such services sustainably and cost effectively, in a fashion that supports comprehensive primary health care, and is sensitive to the cultural perspectives of the clients. Identifying community needs, providing an organisational and coordinating mechanism, and building up regional centres where specialists are based may be good ways to start.

\section{ACKNOWLEDGEMENTS}

The authors would like to acknowledge the contribution of remote community clinic staff and patients who, despite many demands on their time, willingly participated in this evaluation, and the many specialists undertaking outreach activities in the Top End. We are also grateful to others who contributed, the Steering Committee of the Specialist Outreach Service, and Anne Winborne, Ces Farley and Jeanette Raines for facilitating the evaluation. Dr Peter d'Abbs and Associate Professor Ian O'Rourke gave valuable advice and critique.

\section{Authors' affiliations}

R L Gruen, R S Bailie, Flinders University Northern Territory Clinical School and Menzies School of Health Research, Darwin, Northern Territory, Australia

T S Weeramanthri, Centre for Disease Control, NT Department of Health and Community Services, Darwin, Northern Territory, Australia

Funding: Dr Gruen was supported in this work by (1) a Medical Postgraduate Award from the National Health and Medical Research Council, and (2) a Surgeon Scientist Award from the Royal Australasian College of Surgeons Foundation. Additional funding for the programme evaluation on which this paper is based was provided by the Steering Committee of the Specialist Outreach Service in Top End of the Northern Territory.

Conflicts of interest: There are no conflicts of interest in the publication of this work for any of the authors. In particular, Dr Gruen and Dr Bailie were involved as independent evaluators. None of the authors are employed by the Specialist Outreach Service and none stand to personally gain from its continuation or otherwise.

\section{REFERENCES}

1 Bond M, Bowling A, Abery A, et al. Evaluation of outreach clinics held by specialists in general practice in England. J Epidemiol Community Health 2000;54:149-56.

2 Gillam SJ, Ball M, Prasad M, et al. Investigation of benefits and costs of an ophthalmic outreach clinic in general practice. Br J Gen Pract 1995:45:649-52.

3 Black $M$, Leese B, Gosden T, et al. Specialist outreach clinics in general practice: what do they offer? Br J Gen Pract 1997;47:558-61.

4 Spencer NJ. Consultant paediatric outreach clinics: a practical step in integration. Arch Dis Child 1993;68:496-500.

5 Harris A. Specialist outreach clinics. BM 1994;308:1053.

6 Raasen TJ. Airborne surgical outreach services. East Afr Med J 1998;75:561-2.

7 Australian Medical Workforce Advisory Committee. Sustainable specialist services: a compendium of requirements (Report 1998.7). Sydney: Australian Medical Workforce Advisory Committee, 1998.

8 Gruen RL, Bailie RS. Evaluation of the specialist outreach service in the Top End of the Northern Territory. Darwin: Menzies School of Health Research, 2000. View at <http://www.menzies.edu.au> links to Publications and Occasional Papers (Accessed 22 April 2002).

9 Gruen RL, Bailie RS, d'Abbs PH, et al. Improving access to specialist care for remote Aboriginal communities: evaluation of a specialist outreach service. Med J Aust 2001;174:507-11.

10 Australian Bureau of Statistics \& Australian Institute of Health \& Welfare (AlHW). The health and welfare of Australia's Aboriginal and Torres Strait Islander peoples. (ABS catalogue no 4704.0) Canberra: Australian Government Publishing Service, 1999.

11 Ring IT, Firman D. Reducing indigenous mortality in Australia: lessons from other countries. Med J Aust 1998;169:528-33.

12 Eades SJ. Reconciliation, social equity and Indigenous health. Med J Aust 2000;172:468-9.

13 Plant AJ, Condon JR, Durling G. Northern Territory health outcomes: morbidity and mortality 1979-1991. Darwin: Northern Territory Department of Health \& Community Services, 1995.

14 Deeble J, Mathers C, Smith L, et al. Expenditures on health services for Aboriginal and Torres Strait Islander people. (Catalogue no HWE 6). Canberra: Australian Government Publishing Service, 1998

15 McDermott RA, Plant AJ, Mooney G. Has access to hospital improved for Aborigines in the Northern Territory? Aust NZ J Public Health 1996;20:589-93.

16 Ong MA, Weeramanthri TS. Delay times and management of acute myocardial infarction in indigenous and non-indigenous people in the Northern Territory. Med J Aust 2000;173:201-4.

17 Weeramanthri TS. Specialist adult physicians in the Top End of the Northern Territory: an analysis of their number and roles. Australian Health Review 1998;21:50-61.

18 Royal Australasian College of Physicians. Communique of the 1997 Cottrell Conference hosted by the Royal Australasian College of Physicians: Statement on the Delivery of Specialist Services to Remote and Rural Aboriginal and Torres Strait Islander Communities (The Darwin Declaration). Darwin: Royal Australasian College of Physicians, 1997 View at <http://www.racp.edu.au/indig/cottrell.htm> (Accessed 2 March 2001) 